\title{
A Study to Assess the Knowledge and Attitude Regarding Selected Sustainable Development Goals among Peripheral Health Workers Working in Selected PHCs of Anand District
}

\author{
Priyanka G. Talpada*,\#, Siddaram Sarate \\ Manikaka Topawala Institute of Nursing, Charotar University of Science and Technology, Changa, Gujarat, India \\ Email: "talpadapriyanka20@gmail.com
}

How to cite this paper: Talpada, P.G. and Sarate, S. (2019) A Study to Assess the Knowledge and Attitude Regarding Selected Sustainable Development Goals among Peripheral Health Workers Working in Selected PHCs of Anand District. Open Access Library Journal, 6: e5131.

https://doi.org/10.4236/oalib.1105131

Received: December 21, 2018

Accepted: January 19, 2019

Published: January 22, 2019

Copyright $\odot 2019$ by author(s) and Open Access Library Inc.

This work is licensed under the Creative Commons Attribution International License (CC BY 4.0).

http://creativecommons.org/licenses/by/4.0/

\section{Open Access}

\begin{abstract}
The Sustainable Development Goals were framed to address the world's major development challenges with health and its related areas as the prime focus. In India, considerable progress has been made in the field of basic universal education, gender equality in education, and global economic growth but still there is slow progress in the improvement of health indicators related to mortality, morbidity, and various environmental factors contributing to poor health conditions and many more factors were responsible to cause disease. PHWs, who provide all the basic health care to community, also deliver inexpensive, life saving, comprehensive services. They greatly contribute toward achievement of health related SDGs. Objectives of the study: 1) To assess the knowledge of peripheral health workers regarding selected sustainable development goals; 2) To assess the attitude of peripheral health workers regarding selected sustainable development goals; 3 ) To find the correlation between knowledge score and attitude score regarding selected sustainable development goals among peripheral health workers; 4) To find out association between knowledge and attitude with selected demographic variables. Methods: Quantitative research approach with descriptive study design was used and the study was conducted at selected PHCs of Anand district. Total 159 samples were selected by using Purposive sampling technique. Data was collected by using Structured Knowledge Questionnaire and Likert's Scale. Data was analyzed using descriptive and inferential statistics. Results: Result of personal data showed Mean Age of PHWs was $36.459 \pm 7.58$, whereas that majority 138 (86.6\%) were female PHWs and majority 134 (84.4\%) were married about religion, majority 126 (79.2\%) were Hindu, around 112 (70.4\%)
\end{abstract}


had a above 4-year of work experience while majority $112(70.4 \%)$ had got knowledge from health personnel and majority 70 (44\%) had attended training on MDGs/SDGs whereas majority 117 (73.6\%) of ASHAs; regarding level of knowledge out of 154 (96.9\%) had average knowledge, also revealed about majority 156 (98.1\%) had favorable attitude regarding selected SDGs; the correlation coefficient showed there was significant positive correlation found between the knowledge score and attitude score of the PHWs; there was no significant association found between knowledge scores with demographic variable except religion variable, the obtained data $\chi^{2}=7.285(\mathrm{p}<0.05)$ of religion variable. Hence there was a significant association between religion variable with knowledge score. Hence it indicated that there is a significant association between religion variable with knowledge score; there is no significant association found between demographic variables with attitude score. Conclusion: Investigator concluded that $96.9 \%$ had average knowledge and none of peripheral health workers had good knowledge; regarding $98.1 \%$ had favorable attitude, whereas found significant positive correlation between knowledge and attitude score. There was no significant association found between knowledge score with demographic variable except religion variable the obtained data $\chi^{2}=7.285(\mathrm{p}<0.05)$ of religion variable. Hence there was a significant association between religion variable with knowledge score. There was no significant association found between demographic variables with attitude score. Hence it indicated that an average knowledge and favorable attitude of PHWs will ultimately help to Country for achieving SDGs by 2030.

\section{Subject Areas}

Public Health

\section{Keywords}

Knowledge, Attitude, Selected Sustainable Development Goals, Peripheral Health Workers, PHCs

\section{Introduction}

The Millennium Development Goals are eight international development goals that were established following the Millennium Summit of the UN in 2000 till 2015. Then the UN replaces it as the "Sustainable Development Goals" (SDGs), it is also known as Transforming our world and Global Goals: the 2030 Agenda, it covers a broad range of sustainable development issues for the world, such as ending poverty, hunger, improving health and education, combating climate change, etc. The 193 member states have agreed to achieve these new goals by 2030; these 17 goals are further subdivided into 169 numerical targets which are further measured by means of 40 quantifiable indicators. Health constitutes the prime focus of the SDGs. The three goals are directly related to health, and other goals are related to factors which have a significant influence on health (SDGs, 
2017). These goals are: 1) End poverty in all its forms everywhere; 2) End hunger, achieve food security and improve nutrition and promote sustainable agriculture; 3) Ensure healthy lives and promote wellbeing for all at all ages; 4) Ensure inclusive and quality education for all and promote lifelong learning; 5) Achieve gender equality and empower all women and girls; 6) Ensure access to water and sanitation for all. Health has a central place in goal 3, clearly a Peripheral health worker including FHW, MPHW and ASHAs has a major role to play in relation to SDG 3 (SDG platform, 2015) [1].

Goal 1 deals with ending poverty in all its manifestations, including extreme poverty, over the next 15 years. It requires all the basic need of human being and needs to take action on all fronts of water, energy, food security, livelihoods creation, securing the health of natural resources on which the livelihoods of people depend, reducing vulnerabilities, ensuring equity and a just governance framework (UN, SDG Report, 2016) [2] (Anshul B, 2015) [3].

Goal 2 seeks to end hunger and all forms of malnutrition and to achieve sustainable food production by 2030 (UN, SDG Report, 2016) [2]. It is focused on the idea that everyone should have access to sufficient nutritious food. India required around INR 46 lakh crores (USD 729 billion) from 2015-24 for providing access to safe nutritious food for each individual (Anshul B, 2015) [3].

Goal 3 aims to ensure health and well-being for all at all ages by improving $\mathrm{RCH}$; epidemics of major communicable diseases; reducing non-communicable and environmental diseases; achieving universal health coverage; and ensuring access to safe, affordable and effective medicines and vaccines for all (UN, SDG Report, 2016) [2]. India will require around INR 55 lakh crores (USD 880 billion) till 2030 to achieve this value of the Index. But gap which was INR 19 lakh crores (USD 305 billion) is projected with respect to availability of finances for public health in India (Anshul B, 2015) [3].

Goal 4 focuses on quality education for all in order for higher skill, access to all technical, vocational, training and higher education; training throughout life; and the knowledge, skills and values needed to function well and contribute to society (UN, SDG Report, 2016) [2]. India required INR 142 lakhs crores (USD 2258 billion). But still gap of INR 27 lakh crores (USD 429 billion) out of the total of INR 35 lakh crores (USD 555 billion) required for ensuring access to quality early childhood development, care and pre-primary education. Also India will require an additional INR 19 lakh crores (USD 301 billion) for ensuring quality technical, vocational and tertiary education (Anshul B, 2015) [3].

Goal 5 aims to empower women and girls. It mainly focuses on reducing all kinds of discriminations, harmful practices, and has all the opportunity as like men especially including health; access to productive resources; enjoy equal participation with men in political, economic and public life (UN, SDG Report, 2016) [2]. India requires a sum of INR 89 lakh crores (USD 1408 billion) to ensure gender equality by 2030 (Anshul B, 2015) [3]. 
Goal 6 goes beyond drinking water, sanitation and hygiene to also play vital role for community (UN, SDG Report, 2016) [2]. It only depend on people which is critical to the survival of people and the planet, required expanding international cooperation and garnering the support of local communities in improving water and sanitation management Clean Water and Sanitation: India is estimated to require a sum of INR 13 lakh crores (USD 199 billion) till 2030 (Anshul B, 2015) [3].

\section{Need for Study}

More people would grow and develop, more people would learn and know, More people would be equal and just, More children would survive and Livemore mothers would be healthier, More people would be able to combat illness, More people would think of the future, More people would work together (UNESCO). India required about INR 533 lakh crores (USD 8.5 trillion) over next 15 years \& it is mandated for achieving SDGs, According to UNCTAD reports at Global level USD 5 to USD 7 trillion investment required. Whereas need for developing countries was about USD 3.9 Trillion per year only for all basic need including health, water and sanitation, food security, roads, rails and ports, power station, agriculture and rural development, education, climate mitigation \&adaptation; the current investment was in these sector is around 1.4 trillion the huge gap is around USD 2.5 trillion; annual gap between USD 1.9 and 3.1 trillion (Anshul B, 2015) [3].

\section{Methodology}

Quantitative research approach was used in this study. Descriptive research design was used to assess the knowledge and attitude regarding selected sustainable development goals among peripheral health workers working in selected PHCs of Ananddistrict Six PHCs of Anand district was selected from that one was selected for pilot study and remaining five PHCs were selected for the final data collection: In present study sample size calculated by using formula ( $\mathrm{n}=$ $4 \mathrm{pq} / \mathrm{l}^{2}$ ) the investigator got value of 368.64 Sample size. But due to time constrain and limited availability of Sample investigator had collected total 159 peripheral health workers provide services at selected PHCs selected by using Purposive sampling technique: Data collected by using self-administer structured knowledge questionnaire and Attitude scale. Collected data were tabulated and analyzed. Both descriptive and inferential statistics were used to analyze the data collected. Frequency and percentage distribution were used to analyze the demographic data. Mean median, mode and standard deviation of knowledge and attitude score, distribution of scores of knowledge (good, average and poor) and attitude (favorable and Unfavorable), correlation method to find the correlation between total knowledge score and attitude score. Chi-square test used for association of knowledge score, attitude score with 
socio-demographic variables.

\section{Result}

1) Figure 1 Cylinder graph of frequency and Percentage on Level of knowledge of Peripheral health workers [ $\mathrm{N}=159]$.

2) Figure 2 Column graph showing the level of attitude regarding selected SDGs [N = 159].

\section{Discussion}

In present study, the Mean Age of peripheral health workers was $36.459 \pm 7.58$, while the majority $138(86.6 \%)$ were female PHWs and 21 (13.2\%) were male; about marital status, 134 (84.4\%) were married, minimum $1(6 \%)$ divorce, the majority 126 (79.2\%) were Hindu, whereas 13 (8.2\%) Muslim, regarding work experience out of 112 (70.4\%) had above 4 years; whereas very few 15 (9.4\%) PHWs had $<2$ year of experience, data revealed on health related information majority 112 (70.4\%) got knowledge from health personnel and only 7 (4.4\%) got knowledge from friends, while majority 70 (44\%) had attended

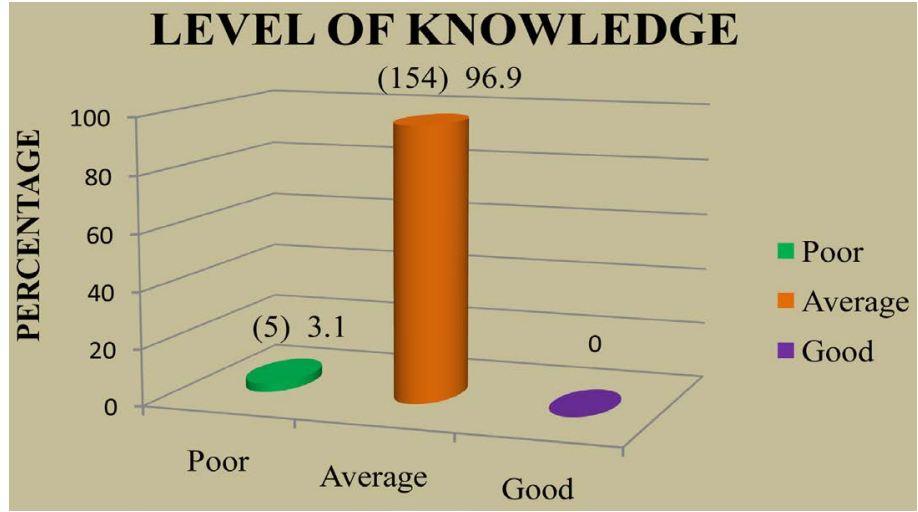

Figure 1. Reveals that majority 154 (96.9\%) had Average knowledge, very few $5(3.1 \%)$ had poor knowledge. Whereas none of them has a Good knowledge regarding selected SDGs.

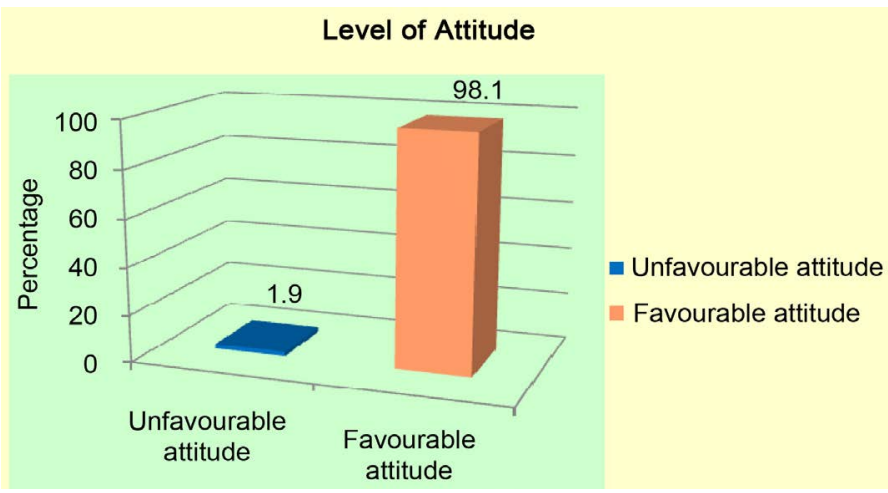

Figure 2. Showed that $3(1.9 \%)$ had unfavourable attitude, whereas majority $156(98.1 \%)$ of had favourable attitude regarding Selected SDGs. 
training on MDGs/SDGs and none of them 89 (56\%) had attended it, about 117 (73.6\%) of ASHAs whereas minimum 20 (12.6\%) were MPHWs:

Regarding knowledge, the majority 154 (96.9\%) had average knowledge, 3.1 (5\%) had poor knowledge, whereas none of them had a good knowledge regarding selected SDGs.

About the level of attitude, very few 3 (1.9\%) PHWs had unfavorable attitude whereas out of $156(98.1 \%)$ had a favorable attitude regarding selected SDGs. The investigator has applied the correlation coefficient formula to find the correlation between the knowledge score and attitude score by using appropriate statistics. The investigator got the value of coefficient of correlation $r=0.244$. Thus the investigator concluded that there is significant positive correlation between the knowledge and attitude of the PHWs working in selected PHCs of Anand District. The present study revealed that there is a significant association between religion and level of knowledge $\chi^{2}$ value $=7.285, p<0.001$ in religion variable is greater than $\mathrm{p}$ value of $\chi^{2} 0.026$ at level of significance with $\mathrm{df}=2$, Hence the obtained chi square value is significant variables religion. There is a significant association found between religion variable and knowledge score.

The obtained values of all variables are less than $\mathrm{p}$ value. Hence the obtained chi square value is not significant. There is no significant association found between demographic variables with attitude score.

\section{Conflicts of Interest}

The authors declare no conflicts of interest regarding the publication of this paper.

\section{References}

[1] Sustainable Development Knowledge Platform (2015) Transforming Our World: The 2030 Agenda for Sustainable Development. https://sustainabledevelopment.un.org/post2015/transformingourworld

[2] United the Sustainable Development Goals Report (2016) http://www.un.org.lb/Library/Assets/The-Sustainable-Development-Goals-Report-2 $\underline{016-G l o b a l . p d f}$

[3] Bhamra, A., Shanker, H. and Niazi, Z. (2015) Achieving the Sustainable Development Goals in India: A Study of Financial Requirements and Gaps Technology and Action for Rural Advancement. http://www.devalt.org/images/L3_ProjectPdfs/AchievingSDGsinIndia_DA_21Sept. pdf? $\mathrm{mid}=6 \& \operatorname{sid}=28$ 